\title{
Tensiones sincopadas y narrativas paradójicas sobre el espacio público en una ciudad fronteriza
}

Alejandro Peimbert. Universidad Autónoma de Baja California, Mexicali, México.

RESUMEN | En la ciudad de Mexicali, México, se encuentra una zona caracterizada por exponer las tensiones entre quien proyecta y dota a la ciudad de espacios públicos, y quien los utiliza y los transforma. Esta zona, conocida como Río Nuevo, es también identificada por su desarrollo dilatado e inacabado. En este artículo se abordan los conceptos de apropiación y asignación, tomando como casos de estudio dos plazas situadas en el sector señalado, en las que se registran ciertas prácticas socioespaciales. La indagación se realiza a través de trabajo de campo etnográfico, y la observación se complementa con el análisis urbano-arquitectónico. Los lugares seleccionados - la plaza Centenario y la plaza de acceso al fex (Centro de Ferias, Eventos y Exposiciones)-, tanto en días festivos como en jornadas cotidianas, son paisajes fronterizos característicos por sus contrastes: modernidad y abandono, institucionalidad e informalidad.

PALABRAS CLAVE | espacio público, transformaciones socioterritoriales, cultura urbana.

ABSTRACT I In the city of Mexicali, Mexico, there is an area characterized by exposing the tensions between those who project and endow the city with public spaces, in front of whoever uses them and transforms them. Known as Rio Nuevo, this area is also identified for its dilated and unfinished development. This article deals with the concepts of allocation and appropriation, using two local places as study cases, where certain socio-spatial practices are recorded through ethnographic fieldwork; the observation is complemented by the urban-architectural analysis. The Plaza Centenario and the FEX (Fair, Events and Exhibitions Center) access square, both on holidays and daily life, are borderlands characterized by their contrasts: modernity and abandonment; institutionality and informality.

KEYWORDS | public space, socio-territorial transformations, urban culture. 


\section{Introducción}

Río Nuevo no es lo que su nombre sugiere. No es un río, sino una formación antrópica, y su origen es ya centenario. Ahora el nombre lo ha adoptado toda una zona que cubre el otrora cauce y que se extiende con una vialidad como eje desde los extremos norte-sur de Mexicali, México, la ciudad capital más septentrional de Latinoamérica.

El paisaje de Río Nuevo evidencia potentemente los contrastes entre la ciudad planeada, la construida y la apropiada. También fragmenta en dos el área urbana, representa el único accidente topográfico en la ciudad y cruza la frontera con los Estados Unidos de América, donde se advierte como un cuerpo de agua expuesto. Se asume que estos choques derivan de las prácticas socioespaciales ejercidas desde el poder, así como desde posiciones contrahegemónicas, y que las tensiones resultantes son mayormente explícitas en los espacios públicos abiertos de esta zona.

El objetivo de este texto es ofrecer una aproximación a los espacios donde se asoman con mayor contundencia las tensiones entre poder y contrahegemonía en Río Nuevo. Para ello se tratará el concepto de 'asignación' como una relación en la que el espacio es dado a los sujetos. Asimismo, se tratará el concepto de 'apropiación', entendida como una relación de los espacios con los sujetos; aquí, estos últimos se sitúan en una posición contrahegemónica. Se hace uso del análisis urbano-arquitectónico como una metodología colaborativa en la que se yuxtapone la observación directa sobre el espacio público, con el registro de ciertos elementos construidos que condicionan o pautan las interacciones entre sujetos. Por su parte, la observación participante detona aquí la producción de datos visuales.

La asignación y la apropiación, tal y como son presentadas en este trabajo, derivan de lo que expone Signorelli (2012) respecto a que existen diferentes modalidades de relaciones entre sujetos y lugares, las cuales representan el papel de los sujetos en esos distintos tipos de relaciones. Las modalidades a las que se refiere Signorelli son la asignación de los sujetos a los lugares, la apropiación de los lugares por los sujetos, y el empaisamiento de los lugares por parte de los sujetos. De acuerdo con la autora, tales modalidades contribuyen a que la recolección de datos y su análisis sean más productivos y permitan afrontar la problemática estudiada en su debida complejidad. Las dos primeras son las que han resultado más pertinentes para esta investigación. Cabe precisar que, lejos de presentarse como una dicotomía, esas dos modalidades constituyen una referencia teórico-metodológica productiva: articulándose con las evidencias empíricas, muestran las tensiones y las narrativas capaces de expresar qué ha venido siendo Río Nuevo y de quién han sido sus espacios públicos.

Se abordarán particularmente los casos de la plaza Centenario y de la plaza de acceso del Centro de Ferias, Eventos y Exposiciones (conocido generalmente como FEX), espacios situados en el corazón de Río Nuevo. El primero se trata de un sitio que alberga una monumental asta de bandera, dado que se erigió como espacio cívico y conmemorativo; el segundo es el ingreso al recinto ferial más grande de la ciudad. Lo expuesto abrevia también un conjunto de registros sobre ciertos recorridos hechos -como un grand tour- de sur a norte. Así, los otros espacios, las infraestructuras y zonas baldías de Río Nuevo representan una suerte de intersticios que se asoman de forma alternada en el presente texto. 


\section{La asignación: poder y espacio dado}

En las ciudades no parece sencillo situar los poderes que determinan cómo moverse, cómo comportarse, cómo andar, cómo hablar o cómo ser, aunque no por ello tal potestad deje de ser esencial para manifestar una posición hegemónica. Foucault lo señala en una entrevista realizada por Rabinow (2015, p. 68): "El espacio es fundamental en toda forma de vida comunitaria; el espacio es fundamental en todo ejercicio del poder". Por su parte, García Canal (2002) ofrece una definición de poder que parte también de las ideas de Foucault.

El poder es una relación en la cual unos guían y conducen las acciones de los otros, es decir, el poder no solo reprime, sino también induce, seduce, facilita, dificulta, amplía, limita y hasta puede prohibir, aunque no es la prohibición la forma más importante, ni siquiera la privilegiada. (...) Para que la relación de poder se dé, es necesario que existan al menos dos, que aquel sobre el que se ejerce el poder sea reconocido, se le mantenga en la relación hasta el final (si se le mata, la relación sin duda desaparece) y que se abra entre ellos todo un campo de posibilidades, de acciones y de respuestas, que se instaure un campo creativo entre ambos. Creativo en el sentido de que siempre aquel sobre el cual se ejerce el poder intenta sustraerse, escapar, hacer trampas, intenta inventar siempre nuevas formas de respuesta que no sean aun conocidas por el que ejerce el poder, para dejarlo, aunque no sea más que por un instante, fuera de la jugada (pp. 37-38).

Por ello, cuando aquí se hable de poder como la modalidad de una relación entre sujetos y lugares -es decir, cuando se refiera al acto de asignar espacios públicos a los sujetos-, resulta más pertinente hablar de tensiones, no de disputas. En una disputa se da la contienda, la batalla o la confrontación, lo cual implicaría el encuentro cara a cara. Es preferible aquí usar el término 'tensión', porque además de que se da la lucha, la hostilidad y la excitación, hay una acción latente, en suspenso. Se trata de una situación en la que las fuerzas que actúan pueden entrar en desequilibrio; por lo tanto, se requiere de otra fuerza (la resistencia o la rebeldía) para que una de ellas pueda ser.

Además de Foucault, es importante contar con el aporte de Sudjic, puesto que ha hecho aportaciones sobresalientes en torno al poder que se ejerce en los procesos arquitectónicos y urbanos. La aportación de Sudjic se refiere a ciertas edificaciones como los palacios, los aeropuertos, los rascacielos, los edificios corporativos e, incluso, los museos, como alegoría del dominio político, económico, social o cultural.

Los poderosos construyen porque eso es lo que les toca hacer. Al nivel más básico, la construcción es una fuente de trabajo que sirve para apaciguar una mano de obra inquieta. Pero también es un buen reflejo de la capacidad y la firmeza -y la determinación- de los poderosos. (...) Es posible que determinado lenguaje arquitectónico no tenga un significado político concreto, pero eso no implica que la arquitectura carezca del potencial para asumir una función política (Sudjic, 2010, pp. 6-11). 
Aunque este autor es más específico, ya que hace alusión a lo arquitectónico, su aporte es pertinente, dado que aquí se hablará de espacios abiertos cuya relación con el espacio instituido es absoluta. La plaza Centenario y la plaza de acceso al FEX son claramente arquitecturas del poder. No solamente por ser equipamientos gestionados por el Estado, sino por incorporar elementos, prácticas y narrativas que promueven el reconocimiento de ese poder.

\section{Apropiación: habitar como resistencia}

Entre la asignación de los sujetos a los lugares y la observancia de los sujetos para seguir las condiciones hechas desde el poder, hay una brecha. En esa brecha se encuentra la apropiación de los lugares por los sujetos: se trata de una segunda modalidad de las relaciones entre sujetos y lugares (Signorelli, 2012). Aunque el acto de habitar no se traduzca de forma inmediata en una transformación física del lugar, las prácticas que derivan de estar en él, de pretender ser reconocido ahí frente a los otros, de marcar (o ver) el lugar para saber dónde se está y, posteriormente, sentirse parte de él, constituyen un construir con los sentidos. Habitar es apropiarse de una porción de paisaje.

La apropiación y resignificación [del paisaje] siempre son procesos que ocurren en un mundo de códigos compartidos con otros. Asimismo, cabe destacar que el paisaje resulta de una dinámica entre fuerzas constituyentes y constituidas, entre lo material y lo social. Los sujetos construyen un paisaje, pero una vez que lo han configurado, ese paisaje influye en sus comportamientos, precisamente porque lo reconocen aun cuando sea invisible para otros (Lindón, 2007, pp. 222-223).

Las fuerzas constituyentes y las constituidas son las que provocan las tensiones entre hegemonía y contrahegemonía, pero lo constituyente en el paisaje no es obligatoriamente lo establecido por el poder. Ciertas prácticas realizadas "desde abajo" por los sujetos pueden desafiar lo institucional. Habitar un lugar puede transformar lo que la planificación y el diseño habían previsto; las prácticas vinculadas al habitar son catalizadoras de las relaciones de apropiación de los lugares por parte de los sujetos; el habitar tiene una capacidad inventiva para que surjan nuevos usos y significados.

Este cambio de la percepción espacio-temporal pone en crisis la idea de que el paisaje es algo estático, así como aquella que asocia habitar con permanencia. ¿La apropiación de los lugares podría darse también bajo condiciones de fugacidad? El espacio público, asignado a una comunidad bajo un estricto control y dotado de dispositivos de seguridad para quienes acceden o hacen uso de él, ¿podría ser transformado a través de prácticas efímeras, y ello considerarse apropiación?

De Certeau repasa una especie de cruce entre la ciudad y lo urbano, exponiendo dos actos que, más que divididos, pueden ser parte de una tensión inherente: ver y practicar. Señala una distancia determinante entre quien planifica el espacio y quien planifica el territorio, lo que convierte la ciudad en un panorama que desdeńa las prácticas; se coloca "arriba" al observador, por encima siempre de los practicantes ordinarios, que permanecen ciegos ante aquello que ellos mismos van trazando en el ir y venir de su vida cotidiana. Existe una ciudad "instaurada" a la cual corresponde 
la organización racional, la sustitución de las resistencias y de las tradiciones y la creación de un sujeto universal y anónimo. Si ver la ciudad se asocia con una posición hegemónica, ¿son las prácticas del andar (las propias de los transeúntes) las que reorganizan y reconstruyen el territorio? Así, "el caminante transforma en otra cosa cada significante espacial. Y si, por un lado, solo hace efectivas algunas posibilidades fijadas por el orden construido (va solamente por aquí, pero no por allá); por otro, aumenta el número de posibilidades (por ejemplo, al crear atajos y rodeos) y el de las prohibiciones (por ejemplo, se prohíbe seguir caminos considerados lícitos u obligatorios)" (De Certeau 2000, pp. 110-111). Harvey, por su parte, nos recuerda las ideas que Lefebvre anotó en los ańos setenta en obras como La ciudad y lo urbano (1978) o El derecho a la ciudad (1976):

Reivindicar el derecho a la ciudad supone de hecho reclamar un derecho a algo que ya no existe (si es que alguna vez existió en realidad). Además, el derecho a la ciudad es un significante vacío. Todo depende de quién lo llene y con qué significado. Los financieros y promotores pueden reclamarlo y tienen todo el derecho a hacerlo; pero también pueden hacerlo los sin techo y sin papeles (Harvey, 2013, p. 13).

El habitar como una práctica de resistencia se manifiesta en la alteración de lo instaurado, en la transgresión de las prohibiciones, en la emergencia de alternativas creativas en torno al uso del espacio; pero también se expone en la revelación de nuevos significados, en la definición de nuevas toponimias y en la aparición de imaginarios que, motivados por determinadas prácticas, inspiran nuevas acciones. Ordinariamente los lugares dan mayormente cuenta del dominio que tiene el Estado sobre ellos. Mientras tanto, lo poco convencional se hace patente cuando -a través de determinados eventos- los espacios cobran vida, rompiendo aparentemente las normas que el poder señala.

\section{Apunte metodológico: etnografía urbana, observación y arquitectura}

Este apartado procura hacer algunas anotaciones metodológicas que argumentan la relación entre la etnografía y el objetivo de la investigación. La etnografía urbana se ocupa de una suerte de nudo intermedio que resulta de las distancias entre las prácticas y los discursos. En este caso este nudo está entre la asignación, como discurso que toma forma -esencialmente- a partir de la arquitectura, y la apropiación, concepto mediante el cual es posible englobar una serie de prácticas asociadas al uso no instaurado de un espacio.

El proceso que siguió este trabajo partió justamente de estos dos conceptos centrales: asignación y apropiación, que -como ya se anotó- fueron recuperados de Signorelli (2012). Para que estos conceptos fueran observables en campo se fueron derivando en categorías y subcategorías de análisis, tales como desarrollo urbano (normar, asegurar, excluir, violentar), uso del espacio (habitar, transitar, abandonar), o sentido de pertenencia. Estas categorías y lo que emana de ellas fueron un punto de arranque: unas fueron perdiendo soporte en campo y otras nuevas fueron resultando. Lo anterior apela por una lógica compleja y un razonamiento emergente. Es decir, en ese nudo intermedio entre asignación y apropiación no hay una tensión 
simple entre prácticas y discursos hegemónicos frente a los contrahegemónicos, sino que coexisten diversos imaginarios y representaciones que arrojan otras preguntas, las que servirían de insumo para nuevas investigaciones.

Los observables directos para hacer etnografía fueron dos espacios públicos específicamente, pero, en general, Río Nuevo siempre fue un ámbito presente, que evitó entender esos dos sitios como unidades aisladas. Después de realizado el trabajo de campo se procedió con un análisis cualitativo, para lo cual fue necesario el uso del software ATLAS.ti.

El trabajo de campo más intenso se inició en abril de 2013 y concluyó en noviembre de 2014. No obstante, fue necesario el retorno a estos espacios en situaciones muy concretas. Por ejemplo, en la plaza Centenario durante los días de izamiento de la bandera, y algunos otros eventos de carácter cívico-institucional llevados a cabo en los ańos 2015 y 2016; entre estos eventos también fue pertinente acudir en ciertos días elegidos de forma aleatoria. Mientras tanto, en el espacio del FEX el retorno se dio en los mismos ańos, con ocasión de conciertos masivos, los cuales exigen un pago por ingresar, o ciertos festivales en donde, aunque hay un control para acceder al recinto ferial, no hay un costo de admisión. Así, aunque hay alrededor de cuatro jornadas muy precisas en las que la etnografía tomó cierta densidad, el trabajo fue iterativo, en virtud de que el análisis de las evidencias no dejara situaciones sueltas.

El análisis devino en un conjunto de textos que han tomado un cierto rumbo hacia la reflexividad. Aquí, el investigador logra saber no solamente más de los sujetos y de los lugares que observa, sino más de sí mismo. Esto es porque hay un "proceso de interacción, diferenciación y reciprocidad" (Guber, 2011, p. 50). Es así que los textos que aparecen a continuación se distinguen por incorporar cierta experiencia sensorial, manifiesta en versiones de lo percibido (Lozano Rivera, 2012); y a ello se incorporan, a su vez, fragmentos donde emergen algunas adjetivaciones.

Los informantes de esta investigación son, en general, usuarios de los espacios públicos. Ellos fueron de diversos perfiles, pues en este caso no fue central la construcción del sujeto, sino las condiciones en que los espacios se presentan y se usan. Pero resaltan ciertos casos, como oficiales de policía, guardias de seguridad de empresas privadas y personal de logística empleado por el ayuntamiento. Estos últimos son informantes situados en el universo de la asignación. Aun con todo lo anterior, no habrá que descartar que de este trabajo pueda proseguir un ejercicio que ponga el foco en ciertos grupos en especial; en estos ámbitos, son los jóvenes, por ejemplo, un sector capaz de dar cuenta de aspectos culturalmente significativos.

En torno a las técnicas empleadas, este texto se centrará en la observación directa y en la observación participante. Además, se incorporan ciertos relatos nativos que se fueron desenvolviendo, algunos de forma más o menos espontánea, en medio de rutinas de observación participante.

Este trabajo se posiciona como un aporte a los estudios socioculturales, en donde el campo se alimenta - al menos en este caso- de las experiencias de la antropología y la sociología urbanas, explorando fenómenos situados en condiciones de frontera y reconociendo las tensiones y conflictos entre sujetos, en un tiempo y un espacio específicos. Siendo así, ¿por qué acudir al análisis de lo urbano-arquitectónico? Son, 
justamente, la antropología urbana y la antropología del espacio las que, a través de experiencias como las de Low (1999), Signorelli (1999) y Giglia (2012), han propuesto la incorporación de nuevos ejes que sugieren puntos de contacto entre las prácticas y el territorio.

El estudio de la cultura en el contexto urbano ha constituido un reto para la antropología, que ha de enfrentarse al análisis de los fenómenos culturales en ámbitos dinámicos, sin fronteras fijas y materializando en prácticas culturales localizadas en diversos lugares o incluso practicadas en el espacio virtual. (...) Actualmente, existe una producción antropológica que describe estos fenómenos y que dirige su atención hacia nuevas formas de análisis de lo urbano en su complejidad actual (...) Low y Lawrence mencionan algunas de estas nuevas cuestiones, tales como los estudios sobre frontera y migración o los estudios sobre nación e identidad. También mencionan aquellos asuntos que plantean fenómenos culturales, multisituados o globales, como el turismo y el sentido de la autenticidad sobre el patrimonio, o los procesos de segregación étnica/clase/género a través de la arquitectura, del planteamiento y del diseńo (Tapada, 2014, p. 330).

Por ello, también se expone el caso de Mexicali como un paisaje fronterizo cuyas identidades urbanas se encuentran en conflicto o, al menos, están expectantes, en medio de un proceso embrionario permanente. La arquitectura sirve aquí como dispositivo central para trabajar en campo a través de una "participación pasiva” en las primeras visitas a los lugares y -paulatinamente- una "participación moderada” y "activa” en los días subsecuentes.

Observar la arquitectura ha sido una carta de navegación para entradas a campo posteriores, en donde se dieron situaciones con mayor involucramiento e intensidad. La importancia de las primeras jornadas reside en que fueron dibujando una suerte de mapas, y esto sirve para "conocer con anticipación la estructura física y social del lugar en la que haremos la investigación, es decir, 'navegar' mentalmente por ella anticipando los obstáculos y las posibles estrategias de investigación a seguir" (Ferrándiz, 2011, p. 71).

En parte, durante las primeras rutinas de observación influyó el trabajo que Georges Perec plasmó en su libro Tentativa de agotamiento de un lugar parisino (2012), anotando y describiendo "todo aquello que por lo general no se percibe, aquello de lo que no solemos darnos cuenta, lo que carece de importancia: lo que ocurre cuando no ocurre nada, solo el paso del tiempo, de la gente, de los coches y de las nubes" (p. 9). Seguir los límites, leer los espacios a partir de sus colindancias y percatarse de las restricciones o de los accesos representó una etnografía de la cual emanan -primordialmente- las relaciones de asignación. 
FIGURA I Intersección del cauce del río Nuevo con el cerco fronterizo con EUA; al fondo se aprecia la ciudad de Calexico, California

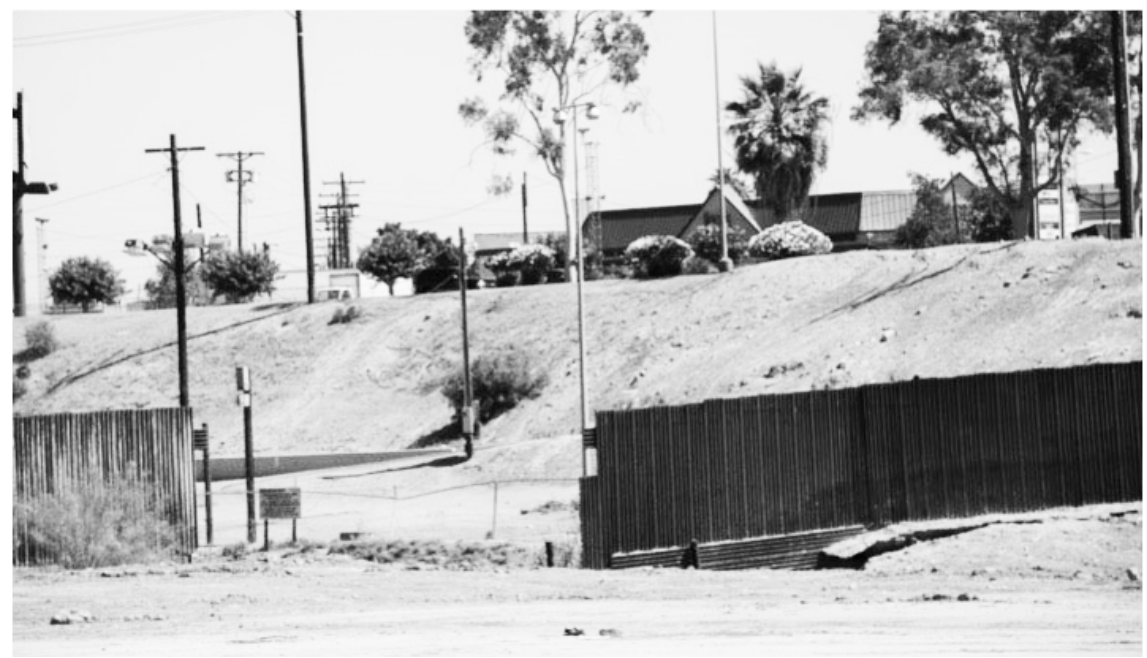

FUENTE ELABORACIÓN PROPIA (2013)

Cabe comentar las restricciones de observar los lugares con una "mirada entrenada" o fotografiarlos con un "lente prejuicioso": el de un arquitecto de formación. En este ejercicio, había que abandonar ciertos conocimientos elementales y centrar la atención en aquello que alimentara la categoría 'asignación', sin inhibir o descartar códigos que, aun siendo básicos en materia de arquitectura, diseño o urbanismo, fueran clave para atender el objetivo de esta investigación. Y, aunque se tratara, en este caso, de hacer etnografía y no análisis urbano o arquitectónico, la ciudad de Mexicali y Río Nuevo son un escenario en el que quien escribe este texto asume el estado de urbanitas local.

Los espacios públicos no solamente son fotografiados en su arquitectura para ilustrar lo que las descripciones vayan presentando, sino que cada imagen representa un dato contenedor de códigos factibles de someterse a un análisis exhaustivo y así construir textos descriptivos derivados del estudio de la imagen, a la vez que dejar que la fotografía revelara aspectos insondables a través de las letras.

La producción de datos visuales y su análisis fueron parte también de un proceso iterativo: una vez obtenida una serie de fotografías, estas fueron yuxtapuestas con el análisis de algunas narrativas orales, para con ello ir perfilando los códigos que se deslizan de la categoría 'asignación' (asegurar, desarrollar, dotar, excluir, normar, desplazar, entre otros) y, posteriormente, regresar a campo para ampliar el registro de fotografías. Estos datos complementan, mas no pretenden sustituir la observación por parte del investigador. Para recoger estos datos no se dio ningún aviso: deliberadamente se pensó como un ejercicio de participación en un espacio público abierto. 
Figura 2 | Plaza Centenario

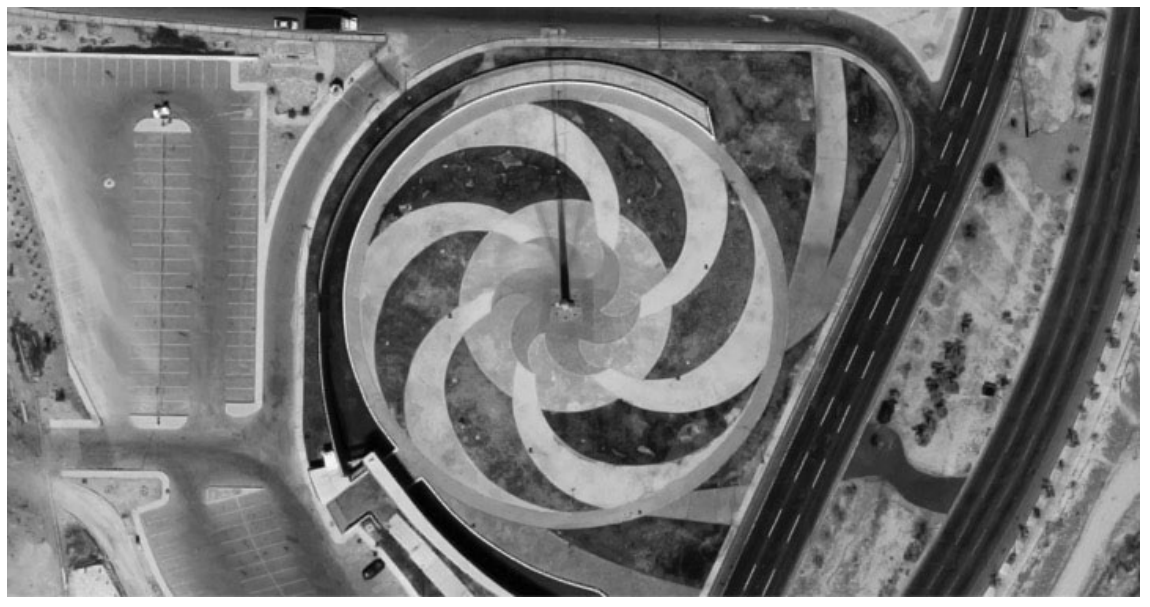

FUENTE ELABORACIÓN PROPIA (20I6)

\section{La plaza Centenario: "No pisen el césped"}

La plaza Centenario se define como una plataforma de concreto circular sobre la que se dibuja la alegoría de una cachanilla, planta silvestre del valle de Mexicali. Dicho trazo sobre el pavimento es solo visible desde el cielo mexicalense que, por cierto, en esta zona no es transitado por el tráfico aéreo; así, dicho emblema es apreciado claramente solo accediendo a Google Maps, o con un dron. Este espacio abierto se ubica en el apéndice del Bosque y Zoológico de la Ciudad, pero le da las espaldas.

Iniciaba el verano de 2013, al centro de la rotonda está un asta de bandera monumental para ser vista -según las promesas del proyecto- desde muy diversos puntos de la ciudad. La bandera se iza esporádicamente; la plaza no se utiliza, no se transita, solo parece contemplarse desde los carros que circulan por el bulevar. Y así, se alcanza a apreciar dominante el mural del artista local Carlos Coronado.

El 9 de diciembre de 2003, día del corte del listón, todo lucía tan pleno, con vida, cada elemento exponía su orden, los jardines florecían, contrastando con ese margen hediondo cubierto de bóvedas de concreto que tiene como vecino. Pero diez años después, tras dos periodos de administración municipal con otro partido político a la cabeza, el lugar no se conservó en buen estado; las banquetas se muestran dañadas, no se observa mantenimiento sobre las áreas verdes, hay elementos vandalizados. Aunque ocasionalmente asiste personal de jardinería, no hay indicios de que algún elemento de seguridad se haga presente. Las fuentes se encuentran apagadas, y en una de las pilas queda agua estancada. La pintura de los muros va perdiendo su tono original, la humedad y el calor han dejado una textura que advierte la capa de otro color expuesta.

No se ven niños jugando, ni familias de paseo. En un lapso de cuarenta minutos de un sábado por la mańana, solo dos personas cruzan la plaza, como tomando un atajo desde la colonia Nueva Esperanza, una de las más cercanas al recinto. Ninguna 
actividad remite a lo que se concibe como un espacio público. La calle, con el tráfico acelerado, hace difícil su acceso; no hay muchos edificios alrededor que provoquen encuentros espontáneos. No hay cruces peatonales evidentes por donde pueda uno llegar. Esta inaccesibilidad refuerza la idea de lo solo y de lo inútil -o de los subutilizado- que parece el sitio.

En los días entre semana, el tráfico vehicular frente a la plaza se incrementa, particularmente por su cercanía con la Facultad de Ciencias Administrativas de la Universidad Autónoma de Baja California. Al mismo tiempo, se observa en el transcurso del día un constante flujo de transeúntes que atraviesa por la banqueta que bordea la rotonda; algunos cortan camino y andan adentrándose a la plaza y saliendo por el estacionamiento posterior. Por su apariencia, es evidente que se trata de estudiantes que se dirigen a la facultad; en la mańana, alrededor de las siete, el flujo se incrementa notablemente, como también al mediodía y en las tardes. Pero ninguno se detiene, como si la plaza fuera un lugar de paso. ¿Sí es una plaza?, ¿sí es un espacio público?, ¿quién lo hace público?, ¿dónde está la gente? Si se observa con detenimiento, tampoco hay bancas, espacios de descanso o elementos que propicien la convivencia. ¿Para quién es ese lugar?, ¿quién hace uso de él?, ¿cómo? Lo relevante no sería responder sucinta e inmediatamente a estas cuestiones, sino partir de estas preguntas para hacer un replanteamiento del programa de necesidades urbanoarquitectónicas de este equipamiento. Un diario local publica el 17 de julio de 2013:

La Plaza Centenario sirvió como sede para que una numerosa cantidad de personas se diera cita desde las 18:30 hrs con banderas blanquiazules para festejar la victoria de manera oficial con los dirigentes que eligieron en el pasado proceso electoral (...) Uno a uno de los coordinadores de partido mostró palabras de agradecimiento al público mexicalense por el apoyo brindado para después ceder el uso del micrófono al próximo presidente municipal Jaime Díaz que inició su discurso cantando una estrofa de la popular canción "El Cachanilla" (Valero, 2013, p. 6A).

El espacio poseía relevancia para aquel candidato electo, quien fuera partícipe de su inauguración. Celebrar ahí el triunfo frente al partido que en ese momento estaba en el poder significaría no solamente recuperar la silla, sino recuperar un espacio abandonado.

Es el mes de abril de 2014, el alcalde que gestionara la creación de esta plaza ya habría asumido por segunda ocasión el cargo. La plaza ha sido sometida a un intenso trabajo de mejora y mantenimiento. Las fuentes producen un enérgico sonido, el lugar se ha tornado en un espacio recurrente para ceremonias oficiales del xxi Ayuntamiento; los trabajos de iluminación dan claras muestras para que la plaza luzca como un espacio emblemático. Hay, en constante vigilia y en tres distintos turnos, oficiales de la policía municipal, uno por turno. Sus jornadas transcurren -la mayor parte del tiempo- sentados bajo el umbral que el muro radial deja para acceder desde el estacionamiento; este espacio se ha rehabilitado también, en sus pavimentos y en sus seńalizaciones.

Una vez rehabilitada, una mampara próxima a un inadvertido acceso señala el nombre del lugar, "Plaza Centenario"; un diagrama argumenta el significado de cada elemento que la constituye, y al pie de la lámina se muestra el logotipo de la 
administración actual. En el contenido, unas líneas expresan: "Espacio de motivación y encuentro de los mexicalenses con su presente y su pasado, en el inicio de nuestro segundo siglo". La frase da por hecho una situación o la promueve, pero a diez años de erigida esto no es una realidad patente.

El césped luce impecable, pero mientras un pequeño grupo de jóvenes se aproxima, el oficial en turno se levanta atento a observar su andar. “ $¡$ No pisen el césped!” indica con voz fuerte pero cansada. Enseguida, se acerca, saluda y con cierto enfado dice: “¡Estos chamacos! No se debe pisar ahí. Aquí es para que luzca bonito, es para la gente, para que lo vean bien”.

El diseño de un espacio cívico puede resultar inhibidor de ciertas prácticas por parte de los usuarios que pensarían el espacio público como lugar de encuentro, como lugar de todos. Aunque la ostentación de un símbolo patrio, la exposición de una placa conmemorativa y la expresión de un enunciado que asevera para qué es un lugar (o para qué fue pensado) no se exhiben como mensajes explícitos de exclusión, sí sirven contundentemente de soporte para acciones verticales que procuran garantizar -al menos- la apariencia de orden, seguridad y limpieza.

\section{El 15 de septiembre desde la comodidad de su plaza}

Mientras que expresiones como "no pises el césped" se asocian con una posición de control (hegemonía) sobre el espacio público, enseguida se abordará la apropiación a partir ya no de las voces, sino de las prácticas. El evento abordado permitió trabajar la observación participante. Sin embargo, en este caso, el rol que tomó mayor peso fue el del participante observador, como aquel que "se desempeńa en uno o varios roles locales, explicitando el objetivo de su investigación. El observador participante [por su parte] pone el énfasis en su carácter de observador externo, tomando parte de las actividades ocasionalmente o cuando le resulta imposible eludirlas" (Guber, 2011, p. 67).

Fue justamente el día en el que se celebraba el llamado Grito de Independencia en la plaza Centenario. Apenas pasaban las siete de la tarde, aún había luz de día. Varios informantes habían comentado que este sitio era frecuentado pocas veces por la gente, y que entre esas ocasiones estaba el 15 de septiembre. En esa fecha, apenas se oculta el sol, cada ańo la gente se reúne a lo largo y ancho de la plaza para apreciar los fuegos artificiales que se encienden desde el Centro Cívico, ubicado a pocos kilómetros de ahí. El evento (para el cual no hay una convocatoria oficial, ni un programa artístico como el que se presencia frente a los edificios de gobierno) se da con muchas menos aglomeraciones y riesgos, lo que permite disfrutar del espectáculo en un ambiente plenamente familiar, similar al de una verbena de barrio.

Para las ocho y media de la noche del 15 de septiembre de 2014, algunas decenas de personas ya se habían instalado en la plaza. El espacio no lucía como en los años inmediatos anteriores. Ahora contaba con mucha mejor iluminación, con todas sus fuentes funcionando, con sus muros bien cuidados, los pavimentos restaurados y el césped en perfecto estado. La bandera estaba a toda asta y las intensas luces aumentaban su imponencia. 
Era notorio que la gente llegaba en grupos, o que al menos arribaban al recinto en parejas. La mayoría lo hacía en automóvil y muchos cargaban con sillas portables, como si aquello se tratara de un picnic. Conforme llegaban los asistentes al espectáculo patrio, los prados se fueron llenando de sillas; también sobre los pavimentos fue ocupándose el espacio de forma libre, pero el público se encontraba francamente orientado hacia el noreste, estimándose que por ahí surgirían los destellos. Quienes llegaron a pie o desprovistos de mobiliario encontraron un buen lugar en el extenso borde de la fuente; precisamente, el muro confina la fuente en sus espaldas, envuelve todo el espacio y se despliega como mirando hacia el Centro Cívico de Mexicali. Destacaba en aquella tarde que por toda la plaza corrían los niños con absoluta libertad, sin restricciones ni llamados por pisar el pasto. Algunos de ellos portaban trajes típicos mexicanos o, al menos, vestían alguna indumentaria alusiva al folclor.

FIgURA 3 | Ronda espontánea alrededor del asta de la bandera en la plaza Centenario

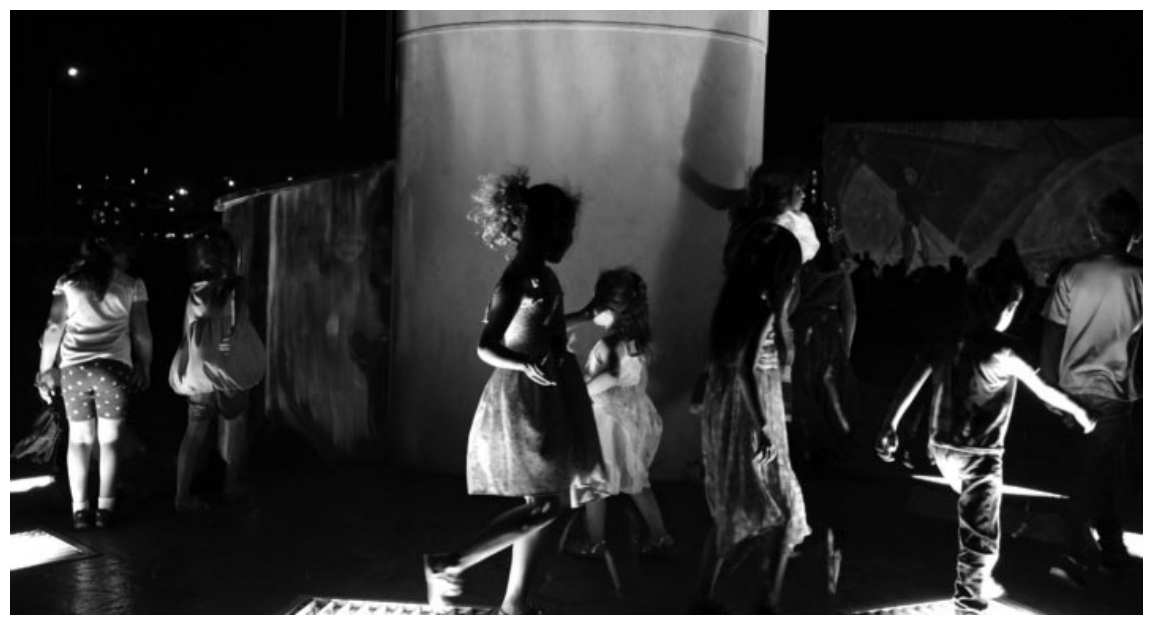

FUENTE ELABORACIÓN PROPIA (20I4)

También desde temprano fue instalándose el comercio ambulante: el vendedor de esquite, el de la nieve de garrafa, el de frituras y golosinas y algunos otros más, sin que fuera algo abrumador. Todos los presentes se mostraban felices en el lugar; en general, se veían expectantes, disfrutando su espera. Aunque aquí no se contempla un programa determinado, tal y como sucedía regularmente, decenas de sujetos seguían llegando, circulaban, jugaban, consumían algún producto y se instalaban para contemplar "los cohetes". En el transcurso de la expectativa se fue dando un par de movimientos, uno centrípeto y el otro centrífugo, que solo podrían manifestarse en este lugar y, muy seguramente, solo en un evento como el de esta naturaleza.

En la plaza, de planta circular, se distinguen dos elementos contundentes: el asta y un mural, realizado por el artista Carlos Coronado. El primero funcionaba aquella vez como una suerte de imán para el encuentro y la sorpresa ante el movimiento de los cuerpos, ya sea jugando, caminando, corriendo, andando en bicicleta o posando 
para una selfie, todo manifestado de forma breve. Los reflectores que realzaban la bandera inducían al juego de los niños más pequeños. Quien se detuviera ahí, de repente se movía, como si hubiera una secuencia de turnos alrededor del centro.

El asta obtuvo un significado nuevo: ya no era un espacio cívico y propicio para rendir honor a la nación, sino un ámbito en el que se celebraba lo espontáneo, lo libre, lo ingenuo y lo fugaz. La atención expectante hacia el cielo despejado para apreciar el inicio de los fuegos de artificio se diluyó. Muchas de las miradas se dirigían al centro, pero ese centro no era la bandera tricolor, ni el águila que se asomaba entre las ráfagas de viento. Los ojos estaban prestos a otro espectáculo: cómo los sujetos se van apropiando del espacio, de forma centrípeta.

FIGURA 4 Espacio abierto frente al mural de la plaza Centenario

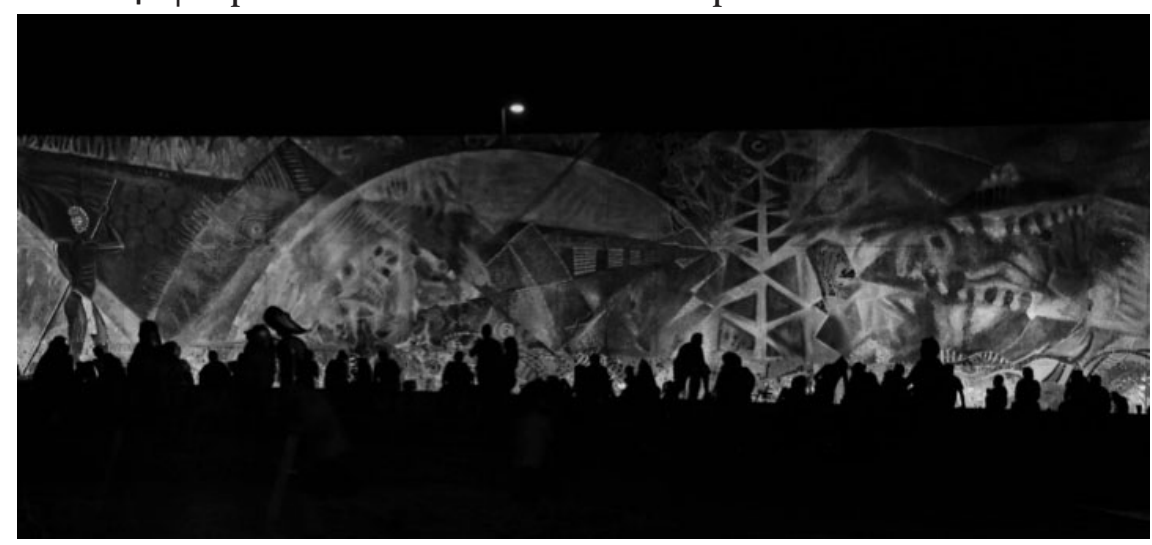

FUENTE ELABORACIÓN PROPIA (20I4)

El segundo elemento en la plaza es el murete al pie del mural artístico, que se ha convertido en banca. Es un sitio solo para estar y ver, donde los sujetos permanecen por periodos extendidos, motivándose conversaciones. Las personas se van sentando y aleatoriamente se forman grupos de forma dispersa; conforme los espacios libres se van reduciendo, la incipiente timidez del encuentro con el otro se va descartando, todo para lograr un buen lugar y estar cómodamente sentado. Enseguida, surgen entre desconocidos pláticas ordinarias: el estado del tiempo, la concurrencia en el sitio, lo cotidiano de la jornada, el por qué estar ahí y no en otro lugar. Algunos le reservan uno de estos improvisados asientos a quien se pasea por la plaza, o a quien compra algo para comer, o a los pequeńos que juegan bajo la vigilancia de sus padres.

El perímetro de la fuente se ha llenado y los que llegan a punto de iniciarse la fiesta de luces permanecen de pie, pero próximos a las orillas, a lo largo del perímetro circular. Desde cierta distancia el mural se reconfigura como un nuevo lienzo, por las siluetas que se empiezan a dibujar. Estas se congelan a las 11 de la noche, cuando se inicia el estruendo de los fuegos artificiales, y se borran enseguida, al tiempo en que, después de 25 minutos, concluyen las detonaciones provenientes del Palacio de Gobierno. Aquel lugar fue mostrándose, poco a poco, tal y como se aprecia comúnmente: vacío e inerte. La plaza Centenario es, en potencia, una de las 
nuevas postales de esta capital bajacaliforniana. Pero nada como esta escena deja en claro que la gente que se apropia de ella, en su centro o en sus orillas, lo convierte en un auténtico espacio público.

Estas prácticas de apropiación por parte de usuarios poco habituales del recinto, pero vecinos del lugar, se contraponen a la asignación del espacio, en donde el control, el desplazamiento y la exclusión han sido condiciones recurrentes, replicándose lo que sucede en toda la zona de Río Nuevo.

\section{Bienvenido, No bienvenido}

El otro espacio estudiado es la plaza de acceso al Centro de Ferias, Eventos y Exposiciones (FEX), lugar que alberga desde el año 2001 las "Fiestas del Sol”, evento anual característico de esta capital, en el cual se dan cita -desde su primera edición en 1976- artistas nacionales de música popular, proveedores de productos tradicionales y de otros no tan tradicionales, juegos mecánicos, y todo aquel que logre hacerse de un espacio para esta celebración, la cual suele coincidir con la despedida del extremoso verano. Con base en un Acuerdo de Creación (2001), el espacio es propiedad del Patronato de las Fiestas del Sol, organismo descentralizado de la administración pública municipal, dirigido y administrado por un Consejo Directivo y un Consejo Ejecutivo. El primero es presidido por el presidente municipal, quien a su vez nombra (a través de una elección pública) al presidente del Patronato, quien al mismo tiempo encabeza el Consejo Ejecutivo. Es, así, una estructura que podría sembrar ciertas dudas respecto a la descentralización de quien administra este equipamiento público.

Según indica su Acuerdo de Creación, el Patronato tiene como objetivos:

I.- Organizar, promover y ejecutar en coordinación con el Ayuntamiento de Mexicali, el evento denominado Fiestas del Sol, así como eventos recreativos y culturales, ferias y exposiciones, que tengan por objeto la promoción de la cultura, los valores y la identidad de la comunidad mexicalense, proyectándose a niveles regional, nacional e internacional; II.- Promover, administrar y operar el centro de ferias, eventos y exposiciones; y III.- Destinar los remanentes económicos obtenidos, al desarrollo de proyectos a favor de la comunidad mexicalense o bien para la asistencia social (Ayuntamiento de Mexicali, 2001).

En los últimos años, además de las Fiestas del Sol, el recinto ha albergado la Villa Navideña, evento llevado a cabo en las fiestas decembrinas y de acceso libre, en que se invita a que los visitantes, al ingresar, cooperen con algún producto que permita llevar despensa a comunidades necesitadas. Los demás eventos que se celebran en el FEX son espectáculos administrados por empresas promotoras de entretenimiento comercial, que hacen posible la visita de artistas de música popular ( $p o p$, rock, música norteña, entre otros géneros) y que alquilan para ello las instalaciones. Los conciertos se dan mayormente en la llamada Isla de las Estrellas y, con menor frecuencia, en un espacio de menor capacidad conocido como la carpa Arte, Pan y Vino. En cualquier evento, la plaza de acceso -sitio sobre el cual se enfocará este texto- es el que exhibe más abiertamente las relaciones de asignación. 
Figura 5 | Muro de acceso al Centro de Ferias, Eventos y Exposiciones (FEX)

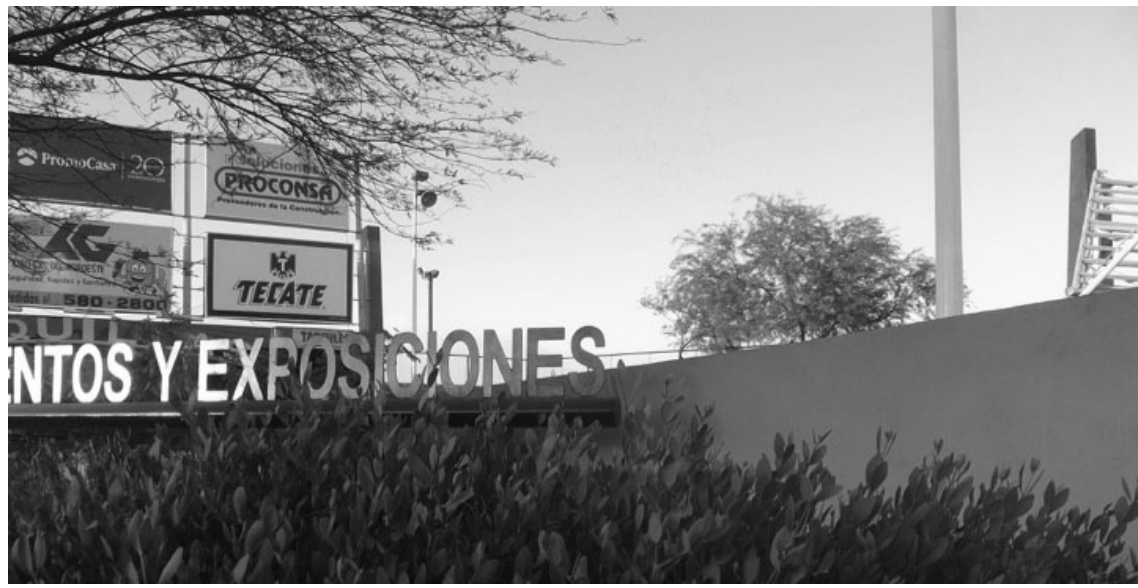

FUENTE ELABORACIÓN PROPIA (2013)

Aquí, los límites que confinan el recinto ferial pueden ser rampas, barandillas, muretes, elementos escultóricos, maceteros o jardineras y edificaciones cerradas, los cuales ofrecen un rico repertorio de formas en las que una delimitación del espacio público puede ser comprendida. Se distingue una jardinera que ordena dos accesos un tanto simétricos. A espaldas de la jardinera se encuentra una fuente, que regularmente solo está en funcionamiento durante las Fiestas del Sol. A lo largo de este elemento delimitante se despliega un muro coronado por el nombre del recinto en letras metálicas; más atrás asoman unos postes con luminarias que, al mismo tiempo, sirven de soporte para unas banderolas.

Figura 6 | Puerta de acceso al fex

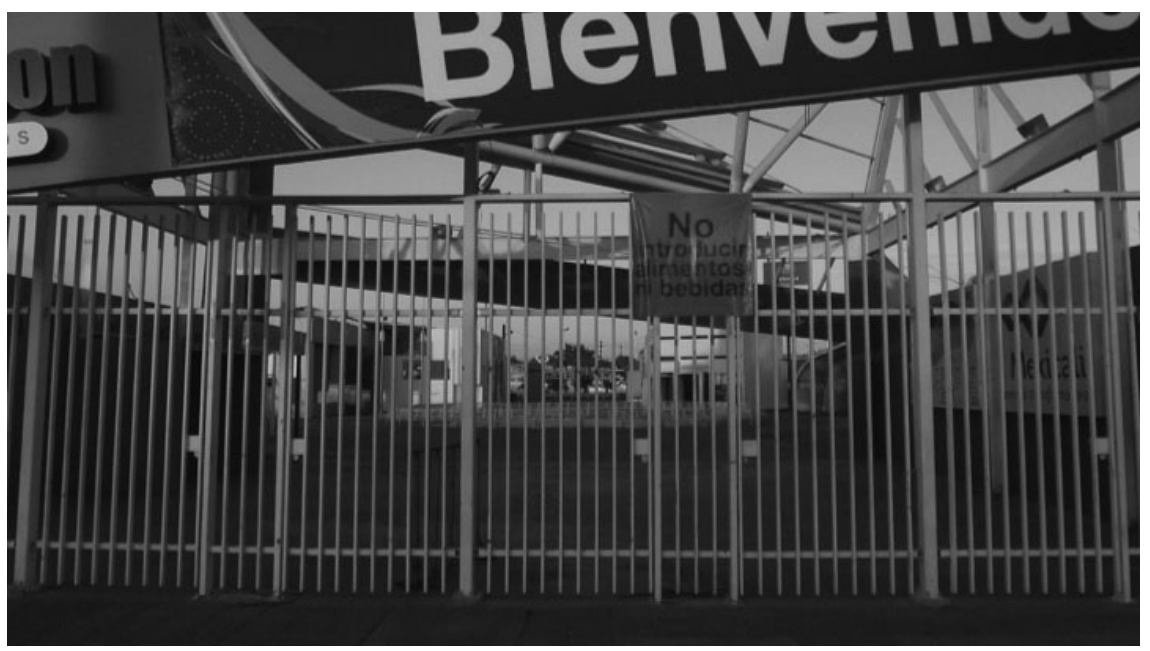

FUENTE ELABORACIÓN PROPIA（2013） 
La plaza, propiamente dicha, está elevada sobre el nivel de la banqueta, de tal modo que los accesos desde la calle se dan por una sucesión de escaleras y rampas. En uno de los bordes del espacio, muy próximo a la puerta de acceso al recinto ferial, se erige una modesta asta de bandera, empleada generalmente en la inauguración de las fiestas. La zona de acceso se distingue desde la Calzada de los Presidentes por su cubierta, conformada por una estructura metálica vertical construida de elementos y materiales aparentes que definen dos planos triangulares.

Bajo esta cubierta, unas marquesinas que dan la bienvenida contrastan con cercas metálicas y con umbrales decorados con lonas que muestran los códigos de comportamiento para hacer posible la entrada. Estos últimos, ocasionalmente, son encabezados por la palabra "No".

Aunque la plaza de acceso no tiene ningún elemento que impida su uso en un día cualquiera, el espacio no propicia ninguna actividad que no sea la espera o el encuentro, siempre y cuando exista un evento. La mayor parte del tiempo es un sitio en desuso, lo cual exige un intenso mantenimiento previo a las Fiestas del Sol. Esto, en cierta medida, consolida la idea de que el espacio público no es del todo público; emblemas de una conocida empresa cervecera, que comparten el colorido juego de elementos y formas con otras empresas patrocinadoras, lo evidencian: es un espacio concesionado.

Por otro lado, una colección de placas metálicas conmemorativas tapiza una de las caras del elemento estructural que define el acceso. Algunas de ellas ya lucen maltratadas, pero todas advierten que se trata, ocasionalmente, de un espacio de ceremonias institucionales, protagonizadas por el gobernador o el presidente municipal en turno. Todo acto político demanda un auditorio. Aquí se aprovecha la concurrencia para emitir un discurso, el cual se explicita en los días de inauguración y queda un tanto subyacente en el despliegue de la imagen del ayuntamiento en turno, de los logotipos, el lema y demás componentes que van construyendo, en primer término, un espacio para la exposición del poder político: qué partido y quién está encabezando el gobierno; y en segundo término, un espacio para la exhibición del poder económico.

En el periodo que duró instalada la Villa Navideña en el invierno de 2014, dentro de la plaza de acceso del FEx se mostraba una proyección en video, con una duración aproximada de cinco minutos. Esta producción audiovisual, exhibida en una secuencia permanente, se refería al programa denominado “300 obras por Mexicali”. En esta, el presidente municipal en turno, Jaime Díaz Ochoa, aparecía en diversos actos, dando el "banderazo", haciendo entrega de alguna obra o recorriendo distintos barrios del área urbana y el valle de Mexicali, acompañado siempre de miembros de las comunidades beneficiadas y de su equipo de trabajo.

Todo elemento alusivo a este festival decembrino venía acompańado de la imagen del ayuntamiento en turno; incluso, en uno se mostraba una bota navideńa con la letra jota: por coincidencia o no, es la inicial del nombre de pila de aquel alcalde. Las ferias del pueblo son el espacio ideal para intensificar las campańas que hacen gala de los proyectos emprendidos y de las metas cumplidas por el gobierno. 


\section{Fiestas del Sol}

El 27 de septiembre fueron inauguradas las Fiestas del Sol en su edición 2014. El presidente municipal ofreció un discurso cuya extensión casi alcanzaba los veinte minutos. Ahí en la plaza, la ceremonia concluía con música de mariachi y con algunos fuegos artificiales. Enseguida, el alcalde y su comitiva ingresaron para hacer un recurrido, acompañados de los medios de comunicación locales. El resto de la multitud se concentraba en la plaza de acceso. Después de dos horas el número de visitantes se incrementó notablemente, ocupándose así buena parte del espacio de ingreso. Algunos esperaban sobre el borde de las jardineras o de la fuente, que tuvo que apagarse enseguida por una falla; otros encontraron lugar al filo de los escalones o sobre los muretes de las rampas; algunos más permanecieron parados, tomándose fotos o entretenidos con su teléfono celular mientras se hacían de boletos. Para entonces, ya se advertía la presencia de una pareja de policías en el lugar. Estaban de pie frente a las taquillas, ambos con gesto amable y apreciando con serenidad el arribo de los visitantes de la feria. Al filo del cruce peatonal, próximo al carril de acceso vehicular al sitio, se encontraba un grupo de policías de tránsito, facilitando el cruce de los peatones que provenían de las zonas de estacionamiento cercanas. El flujo de transeúntes sobre esa senda se iba ampliando conforme se acercaba la noche.

Mientras la gente se iba concentrando en los accesos, cuatro jóvenes - dos hombres y dos mujeres- dispersos en la extensión del lugar entregaban folletos que promovían la contratación de la empresa Telcel. Portaban uniforme y llevaban consigo unos pequeños estandartes de plástico; apenas estuvieron ahí unos diez minutos, advirtiendo el desinterés de los asistentes. Pocos minutos después, dos hombres vestidos con una camiseta con el distintivo de la marca de sopas instantáneas Maruchan ofrecían volantes a quienes cruzaban la calle, como interceptándolos; su labor terminó al tiempo que se les habían agotado las hojas.

Pocos minutos después, aún en medio de la congestión, un joven estacionó su carreta a solo unos pasos del cruce peatonal; en ella cargaba dulces, nueces, semillas y otras golosinas para su venta. No transcurrió mucho tiempo cuando tres sujetos se mantuvieron detenidos junto a él, pero dándole las espaldas. Uno de ellos se distinguía por su pose vigilante del entorno; portaba un radio con el cual aparentaba establecer comunicación de forma intermitente; los otros dos se mostraban como subordinados, no portaban el mismo uniforme que el primero y mientras aquel se desplazaba hacia un punto, los otros seguían sus pasos, como obedeciendo y escoltando. El vendedor de golosinas se acercó a ellos un tanto intrigado. El sujeto del radio, seńalando la carreta y con ademanes que expresaban negación, fue insistiendo en que el vendedor se moviera de ese sitio. Mientras tanto, los subordinados ejercían presión con su sola presencia. Enseguida, el joven fue cubriendo su mercancía y empujando su carreta se desplazó sigilosamente del sitio. Los tres sujetos se mantuvieron platicando ahí un breve instante, para posteriormente abandonar el lugar. 
FIGURA 7 Secuencia que registra el desalojo de un vendedor ambulante del acceso al FEX, el día de la inauguración de las Fiestas del Sol
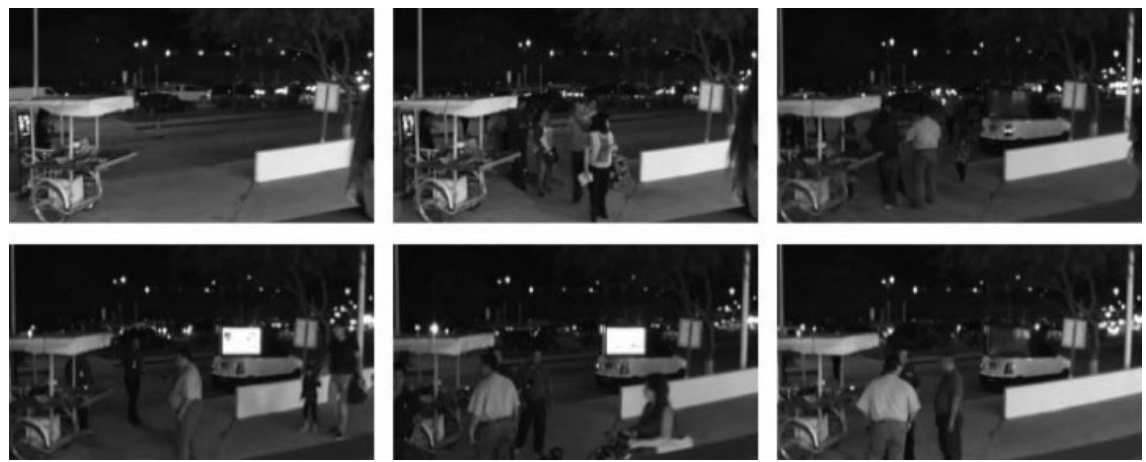

FUENTE ELABORACIÓN PROPIA (20I4)

Al paso de media hora, en la plaza se hizo presente un joven que captó la atención repentinamente. Después de dar algunos pasos seguros hacia uno de los puntos más visibles del lugar, encendió un reproductor de audio; con un vaso en la mano y mostrando una cartulina blanca con el enunciado "LO QUE GUSTE COOPERAR POR FAVOR", empezó a cantar a ritmo de rap. Aun antes de terminada su interpretación, se le acercaron los mismos sujetos que procuraron el desplazamiento de aquel vendedor ambulante. El joven no se inmutó, e incluso siguió con lo suyo con mayor ímpetu. Los sujetos insistieron, se acercaban cada vez más al joven rapero y él, sin detenerse, los esquivaba mientras buscaba otro sitio para continuar. Los sujetos uniformados lo seguían, como escoltándolo. Tras un tercer intento, el joven se retiró del lugar, fastidiado.

Después del altercado, uno de los sujetos uniformados expresó firmemente: “ Nadie puede hacer negocio aquí afuera! (...). Si quieren hacer algo tienen que solicitarlo a los organizadores de las fiestas. Si no, se van a molestar los comerciantes que están adentro... ellos pagan por estar aquî".

Es importante conjugar lo enunciado y lo registrado en campo a través del video. Mientras las voces parecen justificar el acto de desplazar a alguien, aunque ello esté fundamentado más en proposiciones que en un marco normativo, la parte visual alcanza a describir cierta presión y hostilidad de más de dos sujetos sobre uno.

Esta plaza de acceso y los elementos arquitectónicos que la definen no conforman un espacio de tránsito habitual. Al contrario, mientras no haya algún evento en el FEX, el sitio permanece totalmente desolado. Así pudieran darse en él, con toda ecuanimidad, prácticas de apropiación como las recién descritas.

No es el espacio "a secas" el que ejerce un poder -sea cual fuere su dimensión e intensidad-; es el espacio social que se emplaza en ciertos límites, generadores de comunidades e instituciones, los que condicionan o determinan la fuerza del actor o lo debilitan (Vergara Figueroa, 2013, p. 150). 
Con las Fiestas del Sol se exhibe el recinto ferial conocido como fex. Como ya se mencionó, este espacio recibe anualmente, durante dos semanas, una feria tradicional junto con el espectáculo de artistas de música popular. Este y otros eventos aislados y esporádicos son los únicos que le dan vida a este equipamiento. El resto del tiempo permanece como un gran descampado, delimitado, inaccesible y descuidado. En tres canales de video y fotografía, colocados en una misma posición, se observaron -conforme el sol se va ocultando- los posibles usos que adquiere la explanada de acceso principal a las fiestas justo el día de la inauguración, día en el que el alcalde de la ciudad corta el listón y el espacio luce ordenado, limpio, controlado y cuidado.

FIgUra 8 | Plaza de acceso del FEX, antes del acto de inauguración de las Fiestas del Sol

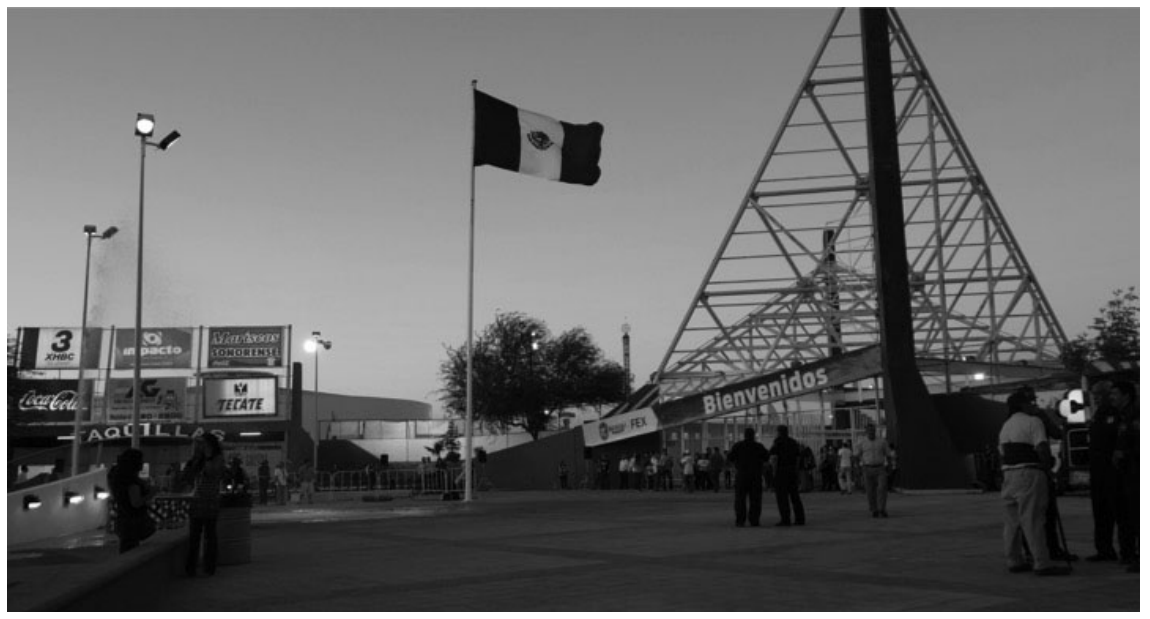

FUENTE ELABORACIÓN PROPIA (20I4)

Se situaron al menos dos cámaras que registraran, ya fuera en fotografía o video, situaciones espontáneas de apropiación de los espacios públicos. La cámara no centró su atención en el evento (motivo del encuentro entre la gente), sino que se dirigió hacia acontecimientos circunstanciales: ingresar a un recinto, esperar, andar, jugar, conversar, entre otros.

Pareciera que esto no cuenta con la necesaria relevancia para una investigación en torno a las tensiones entre la asignación y la apropiación de los lugares. Pero habría que considerar un par de aspectos que resultan clave para interpretar lo que se ha recogido en campo desde septiembre de 2014. Por un lado, Mexicali es una ciudad cuyos espacios públicos padecen de un desuso innegable; es así que la contemporánea crisis generalizada del espacio público se agudiza en una urbe como esta. Aquí, solamente eventos concretos parecen ser capaces de propiciar el uso de lugares de encuentro tales como las explanadas, las plazas abiertas o -incluso, en algunos casos- los parques; pero, salvo escasas excepciones, en el transcurrir de lo 
cotidiano no es común hallar a dos o más personas "estando" en el espacio público. Regularmente estos espacios son remplazados por los pórticos, vestíbulos o galerías de los centros comerciales.

Por otro lado, las condiciones en que se ha desarrollado la zona de Río Nuevo ha propiciado que muchos de los espacios de uso cotidiano por parte de quienes pueblan el entorno de este borde, sean zonas intersticiales: un gran baldío que se convierte en un improvisado campo de fútbol; lugares bajo los puentes que sirven de refugio para indigentes, pues en los parques barriales próximos la policía está vigilante para desplazarlos; los frágiles taludes que son la extensión de los jardines domésticos; o los muros de contención que sirven de soporte para los artistas urbanos.

\section{A modo de conclusión}

En Río Nuevo, hablar de espacio público implica reconocer no solamente la línea difusa que separa lo privado y lo público. Aquí, dentro de aquello que parece de todos, las tensiones sincopadas entre el poder y la contrahegemonía se reflejan en prácticas como proyectar, dotar, normar y asegurar; pero también en excluir, restringir, desplazar o desmontar. A su vez, desde la contrahegemonía la apropiación viene cargada de un conjunto de prácticas que implican acceder, transitar, permanecer, nombrar y marcar; pero también abandonar, desconocer, mudar y destruir.

En cuanto a la plaza Centenario, el Estado procura animarla con monumentos nuevos, con ceremonias cívicas o con mítines partidistas, en un afán de despertarla en medio del sosiego prolongado por el que ha atravesado desde su construcción. En la plaza de acceso del FEx, durante los esporádicos eventos se activan los dispositivos más hostiles de seguridad y control, pero subyacentes en el ambiente festivo, radiante y bullicioso. Con estos eventos, Río Nuevo va consolidándose como paisaje del poder.

Además de lo anterior, hay aspectos que ciertas evidencias han proyectado, y aunque no pasaron por un estricto análisis, sí resulta pertinente incorporarlos a estas conclusiones. Es, precisamente, la versión que aporta lo percibido como urbanitas.

Cuando las familias, los colectivos artísticos y otros sujetos individuales y colectivos hacen suya la plaza Centenario con el encuentro deliberado, el espacio cívico se desmonta para convertirse en la construcción social de un paisaje de la nostalgia. Algunos de estos sujetos - los de mayor edad- añoran lo que Río Nuevo ofrecía como espacio de libertad y esparcimiento. Otros, quizá los más jóvenes, evocan el espacio abierto, libre y de encuentro, reemplazado hoy por los espacios de consumo. Los primeros sujetos son, paradójicamente, los que suelen apreciar con gusto las aparentes bondades que Río Nuevo de hoy en día ofrece: vías rápidas, nuevos equipamientos, arquitecturas formales. Mientras tanto, los segundos van gestionando eficazmente nuevos programas de actividades para la plaza Centenario; acceden a ellas artesanos locales, emprendedores, artistas urbanos y profesionales freelancer, como reconstruyendo provisionalmente la tradicional plaza-mercado. La contrahegemonía va desafiando lo planificado: de día es el espacio de la patria (o de quien esté gobernando); de noche es el espacio del arte y la cultura. 
En el caso del Fex, de momento no existe alternativa para las prácticas de apropiación latentes. Cuando no hay evento alguno, no existe oportunidad para que su plaza de acceso sea utilizada. Pareciera que solo las andanzas de los escasos transeúntes toman el lugar como reposo, bajo la sombra de un árbol, al filo de las escalinatas o sobre los bordes de los muretes perimetrales. Quizá la más clara muestra del debilitamiento del poder es el abandono de los espacios que erige. El deterioro de la arquitectura, las ruinas recientes y el paisaje intersticial conforman la postal más contundente de esta porción de Río Nuevo. La promesa de un enclave privilegiado se desmorona por las prácticas de asignación del espacio público, pero resurge con una agenda alternativa que se apropia felizmente de plazas, parques y espacios inciertos.

\section{Referencias bibliográficas}

Ayuntamiento de Mexicali (2001). Acuerdo de creación del organismo descentralizado de la administración pública municipal denominado Patronato de las Fiestas del Sol de la ciudad de Mexicali, Baja California. Publicado en el Periódico Oficial No. 20, de fecha 11 de mayo de 2001, Tomo cVirI. https://bit.ly/2s1ZS7A

De Certeau, M. (2000). La invención de lo cotidiano: artes de hacer. México: Universidad Iberoamericana.

Ferrándiz, F. (2011). Etnografias contemporáneas: anclajes, métodos y claves para el futuro. Barcelona: Anthropos.

García Canal, M. I. (2002). Foucault y el poder. México: Universidad Autónoma Metropolitana (UAM), Unidad Xochimilco.

Giglia, A. (2012). El habitar y la cultura. Barcelona: Anthropos.

Guber, R. (2011). La etnografía: método, campo y reflexividad. Buenos Aires: Siglo XxI editores.

Harvey, D. (2013). Ciudades rebeldes: del derecho de la ciudad a la revolución urbana. Madrid: Ediciones AKAL.

Lindón, A. (2007). La construcción social de los paisajes invisibles del miedo. En J. Nogué (ed.), La construcción social del paisaje (pp. 217-240). Madrid: Biblioteca Nueva.

Low, S. M. (ed.) (1999). Theorizing the city: the new Urban Anthropology reader. Nueva Brunswick: Rutgers University Press.

Lozano Rivera, C. E. (2012). Etnografía y etnógrafo: percepción y bordes existenciales del trabajo de campo y la etnografía hecha en casa. Revista de Antropología Experimental, (12), 77-89. https://revistaselectronicas.ujaen.es/index.php/rae/article/view/1849

Perec, G. (2012). Tentativa de agotamiento de un lugar parisino. Barcelona: Gustavo Gili.

Rabinow, P. (2015, junio). Espacio, saber y poder: entrevista a Michel Foucault. Bifurcaciones:

Revista de Estudios Culturales Urbanos, (19). http://www.bifurcaciones.cl/2015/06/ reserva/

Signorelli, A. (1999). Antropología urbana. Barcelona: Anthropos.

Signorelli, A. (2012). Sujetos y lugares. La construcción interdisciplinaria de un objeto de investigación. En A. Giglia \& A. Signorelli (eds.), Nuevas topografias de la cultura (pp. 175-198). México: Universidad Autónoma Metropolitana, Juan Pablos Editor.

Sudjic, D. (2010). La arquitectura del poder. Barcelona: Ariel. 
Tapada, M. T. (2014). Sobre el concepto de antropología urbana y de antropología del espacio. En M. Llorente (ed.), Topología del espacio urbano (pp. 303-338). Madrid: Abada.

Valero, G. (2013, julio 17). Celebran en Plaza Centenario. La Crónica, p. 6A. Mexicali.

Vergara Figueroa, A. (2013). Etnografía de los lugares: una guia antropológica para estudiar su concreta complejidad. México: Escuela Nacional de Antropología e Historia, Instituto Nacional de Antropología e Historia. 